\title{
The influence of abusive supervision on work-to- family conflict: the mediation role of organizational justice
}

\author{
Lei $\mathrm{Ju}$ \\ School of Investment and Construction Management, \\ Project Management Research Center \\ Dongbei University of Finance and Economics \\ Liaoning Province, China \\ juleidufe@163.com \\ Zhong Lin \\ School of Business Administration \\ Dongbei University of Finance and Economics \\ Liaoning Province, China \\ linzhongdufe@126.com
}

\author{
Xiuli Jing* \\ Shenzhen Tourism College \\ Jinan University \\ Guangdong Province, China \\ jing_x1@sz.jnu.edu.cn \\ *Corresponding author
}

\author{
Defang Meng \\ School of Business Administration \\ Dongbei University of Finance and Economics \\ Liaoning Province, China \\ littledream999@126.com
}

\begin{abstract}
Using the data of 248 employees' questionnaires, this thesis examined the influence mechanism of abusive supervision on work-to-family conflict from the perspective of organizational justice. The empirical study suggested that abusive supervisor positively affected work-to-family conflict; organizational justice fully mediated the relation between abusive supervision and work-to-family conflict.
\end{abstract}

Keywords- abusive supervision; work-to-family conflict; organizational justice

\section{INTRODUCTION}

A considerable body of research has examined the influence of abusive supervisor on employees' attitudes, performance and behavior in work place ${ }^{[1,2]}$. Abusive supervision is defined as 'sustained hostile verbal and nonverbal behaviors from supervisors, excluding physical contact $^{\text {' }}{ }^{[1]}$. Abusive supervision is associated with a range of negative outcomes including poor employee attitudes toward their job and organization, greater work-family conflict(WFC) and psychological distress, and stronger employee intentions to leave the organization compared with employees who do not work for an abusive supervisor ${ }^{[1,3,4]}$. The researches on the effect of abusive supervision on WFC are already receives more and more attention in academia ${ }^{[5,6,7]}$. However, the research on abusive supervision is still in early stage, and its relation with WFC is an even newer research subject. Few researches analyze on this stress transfer from work to family by "Kicked the dog effect" leading to Work-to-family conflict. Work-family conflict not only affects social stability because of high devoice rate, but also causes negative behavior consequences in organization ${ }^{[8,9]}$, even affects organizational performance and strategic formulation ${ }^{[10,11]}$. The factional mechanism between abusive supervision and WFC is still unclear; the mediation mechanism is still a "black box" needed to be open. Tepper $(2000)^{[1]}$ proposed that the injustice caused by abusive supervision can lead to excessive attention of employee on work from organizational justice perspective. Tepper (2000) ${ }^{[1]}$ brings us a new view on the research of abusive supervision and work-family conflict. But few researches can provide empirical proof on it.

This thesis examined the influence mechanism of abusive supervisor on work-to-family conflict from the perspective of organizational justice. Firstly, based on literature, we gave out the relationship between abusive supervision, work-family conflict and organizational justice. Then, we empirical tested this mediation mechanism using the data of 248 employees' questionnaires. Finally, we made conclusion and gave some managerial implication.

\section{ABUSIVE SUPERVISION, WORK-TO-FAMILY CONFLICT AND ORGANIZATIONAL JUSTICE}

\section{A. Abusive Supervision and Work-to-family Conflict}

The theory of the impact of supervisor on subordinates' stress is the research foundation of the research on impact mechanism of abusive supervision on WFC. Many researchers already pointed out that supervisor can affect subordinates' stressor, and then lead to work stress [12]. As one kind of work stress, the impact mechanism of supervisor on WFC attracts much attention of scholars. Researches mainly focus on social support theory proposing supervisor support can buffer conflict between work and family from positive perspective $[9,13]$. However, there WERE few researches on the negative effect of supervisor. Tepper(2000)[1] proposed that abusive supervision can enhance employees' WFC from negative perspective bring us new research angle, but this only in early stage. Carlson et 
al.(2011)[7] affirmed abusive supervision can positively affect WFC through empirical study. On mechanism, Tepper(2000)[1] proposed that the injustice caused by abusive supervision can lead to excessive attention of employee on work. As a result, they didn't have enough time accompany their family. Then this causes work-family conflict. Restubog et al.(2011)[5] thought abusive supervision can cause psychological distress which increases the aggression of family life, aggravates workfamily conflict. Though the mechanism between abusive supervision and WFC still under debate, abusive supervision can increase employee's work-family conflict is already reach basic consensus in academia. Consequently, we hold the opinion that abusive supervision can positively affect workfamily conflict.

\section{B. The Mediation Role of Organizational Justice between Abusive Supervision and Work-to-family Conflict}

The factional mechanism between abusive supervision and WFC is still unclear; the mediation mechanism is still a "black box" needed to be open. Tepper $(2000)^{[1]}$ brings us a new view on the research of abusive supervision and work-family conflict. Tepper(2000) ${ }^{[1]}$ proposed that the injustice caused by abusive supervision can lead to excessive attention of employee on work. As a result, they didn't have enough time accompany their family. Then this causes work-family conflict. Tepper(2000) ${ }^{[1]}$ reach the conclusion that organizational justice fully mediated the effects of abusive supervision on workfamily conflict, but didn't distinguish work-to-family conflict or family-to-work conflict. Other scholars also gave some evidence on the mediation mechanism of organizational justice between abusive supervision and subordinate's behavior. Burton and Hoobler $(2011)^{[14]}$ found interactional justice ratings to mediate the relationship between abuse perceptions and aggression. Rafferty and Restubog (2011) ${ }^{[4]}$ found interactional justice was observed to mediate the impact of abuse ratings on prosocial silence and voice. Hoobler and Brass $(2006)^{[6]}$ found that subordinate was unlikely to confront an abusive supervisor and instead displaced their anger and frustration in another domain -the home and family sphere -by undermining family members. Therefore, we infer that organizational justice fully mediated the effects of abusive supervision on work-to-family conflict.

\section{METHOD}

\section{A. Sample}

Data were collected from 248 employees from enterprises in Dalian, Tianjin, and Shenzhen in China, including some leading global enterprises, some big State-owned enterprises, and other type enterprises. We send out 387 pieces of questionnaires, took back 312 pieces of questionnaires, and only 248 pieces are effective. In all the participants, $53.2 \%$ are male, and $47.8 \%$ are female.

\section{B. Measures}

1) Abusive supervision. Employees completed a 15-item measure of abusive supervision developed by Tepper $(2000)^{[1]}$. Respondents used a 5-point response scale. An example item is ' My supervisor tells me my thoughts or feelings are stupid'. Cronbach's $\alpha$ was 0.952 .
2) Work-to-family conflict. Employees completed a 5-item measure of abusive supervision developed by Anderson et al.(2002) ${ }^{[15]}$. Respondents used a 5-point response scale. An example item is ' Have you not had enough time for yourself because of your job?'. Cronbach's $\alpha$ was 0.595 .

3) Organizational justice. Employees completed a 3-item measure of abusive supervision developed by Kim and Leung $(2007)^{[16]}$. Respondents used a 5-point response scale. An example item is 'In general, I am fairly treated in this organization'. Cronbach's $\alpha$ was 0.913 .

\section{Data Analysis}

Firstly, we used AMOS to test the structure of the scales. Then we analyzed the influence effect of abusive supervision on Work-to-family conflict, and the mediation mechanism of organizational justice with regression analysis using SPSS.

\section{RESUlTS}

\section{A. Measurement Models}

To assess the factor structure of the measures in the study, we tested a series of confirmatory factor analysis models (see Table I ). The first measurement model estimated the onefactor model. This model was not a good fit to the data, $\chi^{2}=2889.134 ; \mathrm{P}<0.01 ; \mathrm{CFI}=0.534 ; \mathrm{NFI}=0.509 ; \mathrm{IFI}=0.537$; RMSEA $=0.187$. The second to fourth measurement models estimated the two-factor model. These three models were all not good fit to the data. The fifth measurement model estimated the three-factor model. This model was a relatively good fit to the data, $\chi^{2}=2176.256 ; \mathrm{p}<0.001 ; \mathrm{CFI}=0.662 ; \mathrm{NFI}=0.603$; $\mathrm{IFI}=0.664$; RMSEA=0.160. In summary, the hypothesized three-factor model (model 5) was the best fit to the data.

TABLE I MODEL COMPARISONS OF THE MEASUREMENT AND STRUCTURAL MODELS

\begin{tabular}{c|c|c|c|c|c|c|c}
\hline Model & $\boldsymbol{\chi}^{\mathbf{2}}$ & $\boldsymbol{d} \boldsymbol{f}$ & $\boldsymbol{X}^{\mathbf{2}} / \boldsymbol{d f}$ & CFI & NFI & IFI & RMSEA \\
\hline 1 factor model & 2889.134 & 299 & 9.663 & 0.534 & 0.509 & 0.537 & 0.187 \\
\hline 2 factor model & 2742.699 & 298 & 9.204 & 0.561 & 0.534 & 0.563 & 0.182 \\
\hline 2 factor model & 2331.972 & 298 & 7.825 & 0.634 & 0.604 & 0.636 & 0.166 \\
\hline 2 factor model & 2326.629 & 298 & 7.807 & 0.635 & 0.605 & 0.637 & 0.166 \\
\hline 3 factor model & 2176.256 & 296 & 7.352 & 0.662 & 0.630 & 0.664 & 0.160 \\
\hline
\end{tabular}

\section{B. Correlations}

All means, standard deviations, and correlations for the study are reported in Table II. All variables have strong relationship. The relationship between work-to-family conflict and abusive supervision is strong $(\mathrm{r}=0.202, \mathrm{p}<0.01)$. The relationship between work-to-family conflict and organizational justice is also strong $(\mathrm{r}=-0.221, \mathrm{p}<0.01)$, the same as the relationship between abusive supervision and organizational justice $(\mathrm{r}=-0.545, \mathrm{p}<0.01)$.

TABLE II MEANS, STANDARD DEVIATIONS, AND CORRELATIONS

\begin{tabular}{lccccc}
\hline \multicolumn{1}{c}{ Variable } & $\mathbf{M}$ & SD & $\mathbf{1}$ & $\mathbf{2}$ & $\mathbf{3}$ \\
\hline 1. work-to-family conflict & 2.574 & 0.600 & 1.00 & & \\
2. abusive supervision & 1.885 & 0.804 & $0.202^{* *}$ & 1.00 & \\
3. organizational justice & 2.531 & 0.671 & $-0.221^{* *}$ & $-0.545^{* *}$ & 1.00 \\
\hline & & & $* \mathrm{p}<0.05 .^{* *} \mathrm{p}<0.01$.
\end{tabular}




\section{Regression Analysis}

We had one dependent variable in the regression analyses, which is work-to-family conflict; one mediator, which is organizational justice; one independent variable, which is abusive supervision. We entered education, work seniority, and unit's nature as control variables in the first step of the regression, abusive supervision was entered in the second step. All two steps made work-to-family conflict as dependent variable. In the third step, organizational justice was dependent variable, abusive supervision was entered. Organizational justice was added in the final step. Table III presents the results of these regression analyses.

Table III shows that abusive supervision can significantly predict organizational justice after controlling for education, work seniority, and unit's nature $\left(\beta=0.21 ; \Delta \mathrm{R}^{2}=0.038 ; \mathrm{p}<\right.$ $0.01)$. Abusive supervision also can significantly predict workto-family conflict after controlling for education, work seniority, and unit's nature $\left(\beta=-0.50 ; \Delta \mathrm{R}^{2}=0.306 ; \mathrm{p}<0.01\right)$. In the fourth model, when organizational justice entered in the model, the interaction between abusive supervision and workto-family conflict was not significant any $\operatorname{more}(\beta=0.12)$, and $\Delta$ $\mathrm{R}^{2}$ was significant $\left(\Delta \mathrm{R}^{2}=0.016 ; \mathrm{p}<0.05\right)$. These results indicated that organizational justice fully mediate the relationship of abusive supervision and work-to-family conflict. Our hypothesis was supported by the data.

TABLEIII RESULTS OF REGRESSION ANALYSES OF ABUSIVE SUPERVISION AND ORGANIZATIONAL JUSTICE ON WORK-TO-FAMILY CONFLICT

\begin{tabular}{lcccc}
\hline \multirow{2}{*}{ Variables entered } & \multicolumn{2}{c}{ WFC } & OJ & WFC \\
\cline { 2 - 5 } & Model 1 & Model 2 & Model 3 & Model 4 \\
\hline education & 0.02 & 0.00 & 0.08 & 0.01 \\
work seniority & 0.05 & 0.02 & -0.02 & 0.01 \\
unit's nature & 0.05 & -0.03 & $0.15^{*}$ & -0.01 \\
abusive supervision & & $0.21^{* *}$ & $-0.50^{* *}$ & 0.12 \\
organizational justice & & & & $-0.16^{*}$ \\
$\mathrm{R}^{2}$ & 0.005 & 0.042 & 0.333 & 0.058 \\
$\Delta \mathrm{R}^{2}$ & 0.005 & $0.038^{* *}$ & $0.306^{* *}$ & $0.016^{*}$ \\
\hline
\end{tabular}

$\mathrm{WFC}=$ work-to-family conflict; $\mathrm{OJ}=$ organizational justice

${ }^{*} \mathrm{p}<0.05 . * * \mathrm{p}<0.01$

\section{DISCUSSION}

The purpose of our study was to explore the mediation mechanism of organizational justice on the relationship of abusive supervision and work-to-family conflict. Our research found that organizational justice fully mediate the relationship between abusive supervision and work-to-family conflict. Our study contributes to knowledge about handle style of perception of abusive supervision, and how it transfer to family domain. Refer to our finding, abusive supervision influences work-to-family conflict fully through organizational justice. So enterprises can control the negative consequence through enhancing employees' perception of organizational justice.

\section{ACKNOWLEDGMENT}

This research was funded by the National Natural Science Foundation of China (71172119, 71302139, 71102092, 71402019), the Youth Project of Humanities and Social
Science Foundation of Chinese Ministry of Education (14YJC630054) and the Youth Project of Scientific Research Foundation of Dongbei University of Finance and Economics (DUFE2014Q46).

\section{REFERENCES}

[1] B.J. Tepper, "Consequences of abusive supervision", Academy of Management Journal, vol.43, pp.178-190, 2000

[2] B.J. Tepper, "Abusive supervision in work organizations: review, synthesis, and research agenda", Journal of Management, vol.33, pp.261-289, 2007.

[3] Tepper, B. J., M. K. Duffy, C. A. Henle and L. S. Lambert. "Procedural injustice, victim precipitation, and abusive supervision", Personnel Psychology, vol.59, pp.101-123,2006.

[4] Rafferty, A.E. and S.L.D. Restubog, "The influence of abusive supervisors on followers' organizational citizenship behaviours: the hidden costs of abusive supervision”, British Journal of Management, vol.. 22, 270-285 (2011)

[5] S.L.D. Restubog, K.L.Scott, and T.J.Zagenczyk, "When distress hits home: the role of contextual factors and psychological distress in predicting employees' responses to abusive supervision", Journal of Applied Psychology, vol.96, pp.713-729, 2011.

[6] J.M. Hoobler and D.J.Brass, "Abusive supervision and family undermining as displaced aggression" , Journal of Applied Psychology, vol.91, pp.1125-1133, 2006.

[7] D.S. Carlson, M.Ferguson, P.L.PerrewÉ, and D.Whitten, "The fallout from abusive supervision: an examination of subordinates and their partners", Personnel Psychology, vol.64, pp.937-961, 2011.

[8] S. Parasuraman, J.H. Greenhaus and C.S. Granrose, "Role stressors, social support, and well-being among two-career couples", Journal of Organizational Behavior, vol.13, pp.339-356,1992,

[9] D.S. Carlson and P.L.Perrewé, "The role of social support in the stressor-strain relationship: an examination of work-family conflict", Journal of Management, vol.25, pp.513-540,1999.

[10] J.D. Goodstein, Institutional pressures and strategic responsiveness: employer involvement in work-family issues, Academy of Management Journal, vol.37, pp.350-382, 1994.

[11] J.E. Jennings and M.S. McDougald, "Work-family interface experiences and coping strategies: implications for entrepreneurship research and practice", Academy of Management Review, vol.32, pp.747-760, 2007.

[12] T.W. Britt, J.Davison, P.D.Bliese, and C.A.Castro, "How leaders can influence the impact that stressors have on soldiers", Military Medicine, vol.169, pp.541-545, 2004.

[13] L.T. Thomas and D.C.Ganster, "Impact of family-supportive work variables on work-family conflict and strain: a control perspective", Journal of Applied Psychology, vol.80, pp.6-15, 1995.

[14] J.P. Burton, and J.M. Hoobler, "Aggressive reactions to abusive supervision: The role of interactional justice and narcissism," Scandinavian Journal of Psychology, vol. 52, no. 4, pp. 389-398, 2011.

[15] C. Anderson, and, E.B.A. Stella, S.C. Betty, and T.B. Robin, "Formal organizational initiatives and informal workplace practices: links to work-family conflict and job-related outcomes". Journal of Management, Vol. 28, pp. 787-810, 2002.

[16] Kim, T., and Leung, K.. "Forming and reacting to overall fairness: Across-cultural comparison", Organizational Behavior and Human Decision Processes, Vol. 104, pp. 83-95, 2007. 